\title{
The usefulness of Usability and User Experience evaluation methods on an e-Learning platform development from a developer's perspective: A case study
}

\author{
Aldo Gordillo, Enrique Barra, Sandra Aguirre and Juan Quemada \\ Escuela Técnica Superior de Ingenieros de Telecomunicación \\ Universidad Politécnica de Madrid \\ Avenida Complutense 30, 28040, Madrid, Spain \\ \{agordillo, ebarra, saguirre,jquemada\}@dit.upm.es
}

\begin{abstract}
The development of a web platform is a complex and interdisciplinary task, where people with different roles such as project manager, designer or developer participate. Different usability and User Experience evaluation methods can be used in each stage of the development life cycle, but not all of them have the same influence in the software development and in the final product or system. This article presents the study of the impact of these methods applied in the context of an e-Learning platform development. The results show that the impact has been strong from a developer's perspective. Developer team members considered that usability and User Experience evaluation allowed them mainly to identify design mistakes, improve the platform's usability and understand the end users and their needs in a better way. Interviews with potential users, clickmaps and scrollmaps were rated as the most useful methods. Finally, these methods were considered unanimously very useful in the context of the entire software development, only comparable to SCRUM meetings and overcoming the rest of involved factors.
\end{abstract}

Keywords-Usability; User Experience; e-Learning; evaluation methods; software development

\section{INTRODUCTION}

Usability and User Experience (UX) play an essential role in the development of successful e-Learning applications. If an e-Learning system is not usable enough, their users will have to spend a lot of time learning how to use the software and as a consequence the system will hamper them from performing their tasks in a profitable way. Given that, ensuring a good usability and UX to the largest number of users should be one of the main aims of e-Learning application developers and designers. So, they need appropriate guidelines as well as useful and effective evaluation methods to implement usable interfaces. Despite the recent research and advances in the usability and UX evaluation field, a consolidated evaluation methodology for e-Learning systems is not available yet and a consensus about what evaluation methods are more useful has not been reached either. Moreover, there is still a gap between research and practice as many evaluation methods and studies are kept in the academic field and they are never translated into practice [1]. In fact many software companies are not even aware of UX [2]. Finally, there is little information about how the usability and UX evaluation influences the software development cycle.

Although good usability and UX does not guarantee success, a bad one is nearly always a quick route to failure [3]. With this concern in mind the GLOBAL excursion (Extended Curriculum for Science Infrastructure Online) project started in 2011 following a user-driven design process.

GLOBAL excursion [4] is a technology-enhanced learning project, especially targeting towards providing support for innovative science teaching in schools. To host the project activities an open source web e-Learning platform called Virtual Science Hub [5] (ViSH, available at http://vishub.org) has been developed. Scientific institutions and research labs can share their resources in $\mathrm{ViSH}$, thus address a young target group of potential future scientists and gain visibility. Teachers can use these resources to improve their science teaching [6]-[8]. Finally, as ViSH is a social network, both teachers and scientist can meet and collaborate together for the improvement of science teaching.

Each stage of the ViSH development has been addressed with different usability and UX evaluation methods, depending on the tools available, the budget, the time span, etc. The perceived usefulness and influence of these methods differ among the development team members. Some of the used methods are preferred to others and the influence of the feedback received varies from one to another.

This paper presents a study of the perceived usefulness of the different usability and UX evaluation methods applied in the development of the ViSH platform, including its results and the lessons learned. We will also give some tips to make these methods more persuasive to the development team.

The rest of the paper is organized as follows. The next section reviews related work in the area of usability and UX. Section 3 describes the setting and research design used in this case study. Section 4 presents the used usability and UX evaluation methods. Section 5 describes the results of the study. Finally, the last sections provide some discussion and concluding remarks together with an outlook on future work and some tips for usability and UX practitioners. 


\section{RELATED WORK}

The International Standards Organization (ISO) defines usability as "the extent to which a product can be used by specified users to achieve specified goals with effectiveness, efficiency and satisfaction in a specified context". This definition can be found in the document "ISO 9241-11 (1998) Guidance on Usability" [9]. There are several usability evaluation methods such as analytical, expert heuristic evaluation, surveys by questionnaires, observation or experimental methods ([10], [11]), which usually present a trade-off between cost and effectiveness. Despite a consolidated usability evaluation methodology for e-Learning systems is not available yet, a first step in this direction can be found in [12], where specific usability attributes of e-Learning applications were identified. Regarding usability evaluation on e-Learning platforms, a related work can be found in [13], where a web-based e-Learning platform was evaluated using a system based on usability and pedagogical usability evaluation.

The term User Experience (UX) was first invented by Donald Norman in 1995 in his paper on Human Interface at Apple Computer [14]. The notion itself has evolved until today, where the more "formal" or "official" definition can be found in ISO 9241-110:2010 (clause 2.15). UX is defined in this standard as "a person's perceptions and responses that result from the use and/or anticipated use of a product, system or service" [15]. This commonly referenced definition can be complemented with many others found in books or research papers (see [16]). The common terms/words that appear in most definitions are user's "feelings", "perceptions" and "satisfaction". Other characteristics that help to understand the UX concept are "dynamic", as it changes over time as the circumstances change, "subjective", because it is about an individual's performance, and "context-dependent" [17].

Depending on the scenario and on the expert consulted the UX can be measured quantitatively [18] or qualitatively [19]-[21]. With regard to the time span [22] the UX can be measured before usage (i.e. imagining usage), during usage, (i.e. while experiencing), after usage, (i.e. reflecting on an experience) or over time (i.e. collecting multiple periods of time). Other features like time restrictions, place of evaluation, type of participants or expertise required can help us characterize the different UX evaluation methods. In [23], we can find a list of 96 UX evaluation methods, but it is not a closed list as UX is a quite recent research area and those 96 methods can be combined, modified or even new ones can be defined and modeled using existing or new technologies.

Software development life cycle can be divided into several phases: requirements analysis, design, implementation, testing and maintenance. Although there are variations in their application, different methodologies apply this process either to the whole product or system (waterfall model), or to each iteration (iterative or spiral model), or to a single feature (agile development).

In its relation with software development, UX is being the focus of many research studies [24]. Although software engineering is a mature field and many methodologies exist and are established, new methodologies still appear and in their relation and integration with UX give place to new researches [25]. The same way as UX can be combined with different methodologies it can likewise be applied to different development phases. Although some authors state that early phases are more important for UX [26], UX evaluation is present in all phases of software development, from scenarios or concepts to products on market, including early and functional prototypes.

\section{STUDY DESIGN}

The study design took into account the whole software development process, all the usability and UX methods that had been used, and a survey among the team members. This survey was conducted together with short interviews to discover the usefulness and effects of the different evaluation methods in the labors of the development team members. The main aim of the study was to evaluate the impact of usability and UX in the software development, analyzing the outcomes of the surveys, interviews and the methods themselves.

Fig. 1 illustrates the study design, including usability and UX evaluation methods, software development milestones and other factors that might have influenced software development like important meetings or documents, connecting all of these items through a timeline.

The timeline starts at the moment that GLOBAL excursion project was approved. Its planning was defined in the "Description of Work" (DoW) document. Three months later, the first alpha version was released. Since then, two main releases of ViSH have been deployed, the first of them one year after the project started and the second one six months later.

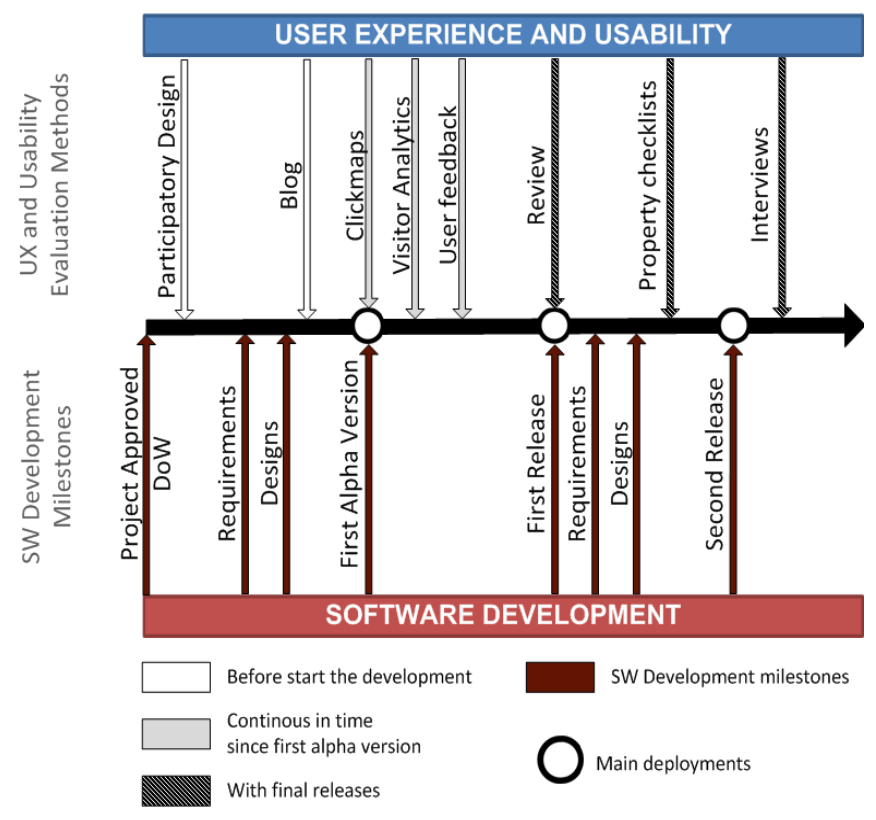

Fig. 1. Study design 
The ViSH platform has been developed following an Iterative and Incremental Development (IID) life cycle. Iterative development is an approach to building software (or anything) in which the overall life cycle is composed of several iterations in sequence. Each iteration is a self-contained mini-project composed of activities such as requirements analysis, design, programming, and test [27]. In each iteration a slice of functionality is delivered from the requirements to an implementation ready to deploy.

In order to encourage agility, we introduced into our software development life cycle some methods based on the agile development principles. We introduced SCRUM meetings [28] and some XP (eXtreme Programming) practices like pair programming, frequent refactoring or coding standards. The inclusion of these methods did not involve a radical change since agile methods are basically a subset of iterative and evolutionary methods. Also, we used technologies that encourage agile development such as Ruby on Rails, an open source web application framework which was designed with agility as part of its structure [29].

On the other hand, usability and UX evaluation methods have been used from the beginning of the GLOBAL excursion project until today, influencing each development stage. Feedback from different sources was identified as relevant for this case study: developers, end users, potential users (people that have never entered the platform but that have a profile that make them target users) and European reviewers. To gather the feedback we used a combination of different usability and UX evaluation methods. So, depending on the development stage, we used different methods such as workshops, direct feedback, analytics tools integrated in the platform, interviews and so on. All these methods are explained in the next section.

\section{USABILITY AND UX EVALUATION METHODS}

Some of the usability and UX methods presented in this section and used in the development of the ViSH platform are one-time methods (e.g. interviews) and other are continuous in time, since they were based on analytics tools added to the platform (e.g. clickmaps). Other features that we will use to characterize the methods used are based on the factors identified and defined by Alan Dix in his book Human-computer interaction [30]. These are stage in the cycle at which the evaluation is carried out, style of evaluation, level of objectivity, type of measures provided, information provided, immediacy of the response, intrusiveness and resources required.

When choosing methods for a usability study many issues should be considered such as the goals of the study, the participants, the technology that is available to collect and analyze the data, the budget and the available time [31]. Taking these issues into account the development team selected a combination of usability and UX evaluation methods. The application and coordination of these methods were done by the project manager together with the two most senior developers. Now we will explain the different usability and UX evaluation methods used in the development of the ViSH platform.

\section{A. Participatory design methods}

Participatory design is a wide field that considers different methods, techniques and practices [32]. All of them involve the target users in the design of the platform. In the ViSH case five external teachers were involved as pedagogical advisors. Also the scientific partners of the consortium and some members of the development team participated in these methods. They were performed on two phases, initial interviews with teachers and a participatory workshop.

\section{1) Interviews with teachers}

As a preparatory step semi-structured interviews were conducted with the participating teachers via telephone. The aim of these interviews was to explore the background of the participants, gather specific aspects and experiences of their working practices and how they use ICT in their teaching and transfer this to the developers and scientists. This information was used to prepare the participatory workshop.

This is a one-time method, performed in the phase "requirements analysis" of the first iteration and it is totally subjective and qualitative, as teachers are providing their opinion, their way of using ICT, the structure of their lessons, etc.

\section{2) Participatory workshop}

It was held in Vienna, where teachers, scientists and developers were interacting and designing scenarios using different techniques. User scenarios are "informal narrative descriptions" [33] about hypothetical archetypes of actual users, usually called personas, and their activities, emphasizing the goals the user wants to reach with a specific product, the persona's expectations concerning particular systems and the most critical tasks that she wants to execute [34].

The scenarios were the final outcomes of the workshop, which started to go into further detail of teachers work via an Artifact Walkthrough [35]. Teachers brought artifacts and talked about their complex daily work processes. Scientists on the other hand gave a presentation and hands on sessions on their specific infrastructures they can offer to the teachers. During that process feedback was gathered and visualized. In a final step, teachers, scientists and developers jointly developed future scenarios. More details about the workshop can be found in [36].

This is a one-time method and it was done in person, using different rooms for the activities, whiteboards, notebooks, etc. The phase where this method was done is "design" of the first iteration, it is subjective and qualitative. The style of evaluation is in laboratory.

\section{B. Sharing the designs in a blog and get feedback through comments}

After the participatory design and before starting the development, some wireframes for the ViSH were created by the designers with the features derived from the scenarios designed in the previous evaluation phase, trying to enhance the identified benefits and trying to avoid the identified barriers. 
These wireframes were shared in a blog [37] and teachers and scientist were asked to give their opinion, if they missed something or if they did not understand anything. This feedback was reported in the blog as comments and was useful for detecting problems with the designs and for checking if teachers and scientists liked the design line.

This is a one-time method. In this moment, we were still in the design process of the first iteration. This is a subjective and qualitative method.

\section{Visitor analytics}

Visitor analytics is a method that is very cheap and quite interesting to measure some usability factors like page loading time, page views, visitors' flow and statistics about user activity in the page.

The tools that we have used to measure it are server logs and Google Analytics. The measure is objective and quantitative. This is a continuous in time method which has been running since the first deployment.

The main outputs of this method are the logs files, which sometimes have to be parsed and simplified in order to make them easier to read, and the charts, graphs and tables obtained from the Google Analytics tool.

\section{Clickmaps and scrollmaps}

Clickmaps provide screenshots of the platform with information of what zones the user clicks. Scrollmaps provide the same screenshots but this time with information about the percentage of users that scrolls to the top or the bottom of the page (see Fig. 2). We used the tool CrazyEgg [38], which is cheap and one of the best known tools in this area.

As well as visitor analytics method, these ones are continuous in time and were available since the first deployment. Measures obtained with these methods are objective and quantitative.

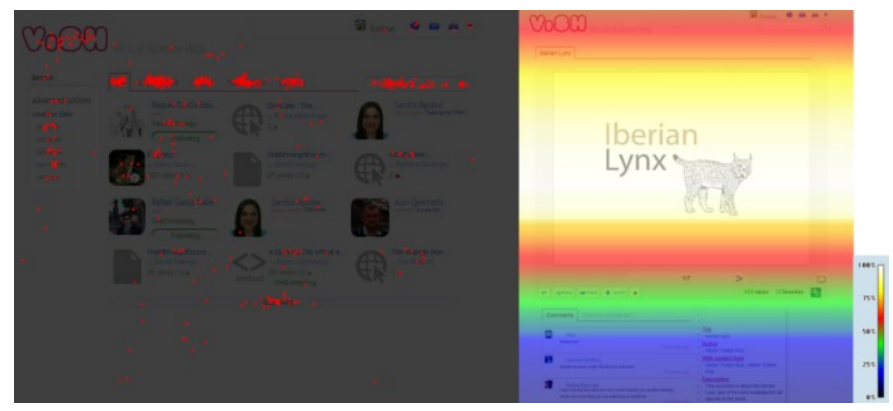

Fig. 2. Clickmap and Scrollmap

\section{E. User feedback}

Three tools were used to gather explicit user feedback.

- Videoconference sessions with the five teachers participating in the project and with scientific partners (see Fig. 3). The selected tool for this task was MashMe.tv [39].

- Feedback tool integrated in the web platform accessible through a button fixed in the left side. This tool was Uservoice [40].

- Direct email. Teachers and scientist have the ViSH contact email to report feedback. Also people that first reported via Uservoice got an email response solving their issue and/or thanking for the feedback. Later, these people usually used this same email address to report the rest of their gathered feedback.

The videoconference is a one-time method while feedback tool and email are continuous in time. Reported feedback sometimes is objective (e.g. bug notifications) and sometimes subjective (e.g. impressions or experiences).

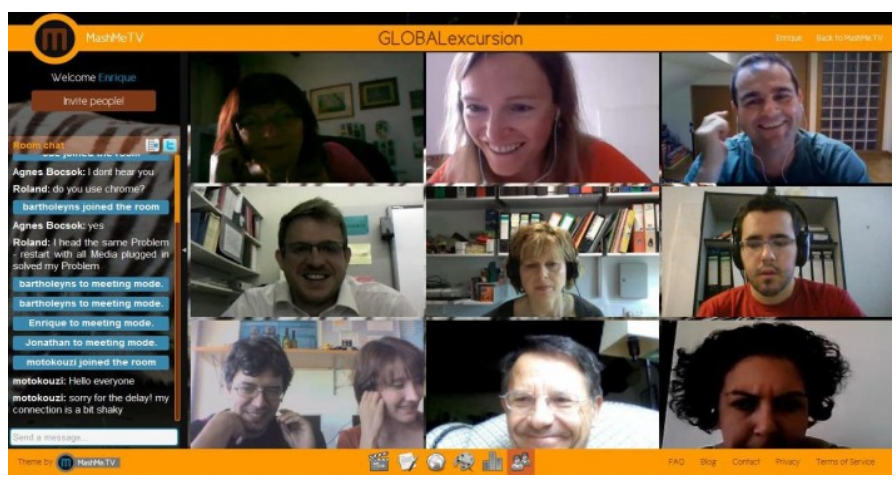

Fig. 3. Videoconference session among GLOBAL excursion consortium members and teachers

\section{F. Project review by European Commission reviewers}

Given that this platform has been developed in the context of a European project, a review was performed after the first year of the project, coinciding with the first main release of the e-Learning platform. In contrast to the other methods, this one was not chosen by the development team but, as this review gave additional feedback on the development of $\mathrm{ViSH}$, it was considered as another evaluation method.

The review was done via videoconference where two external experts and one European Commission official representative gave their opinion about the platform, the figures (number of users and resources in ViSH, page rank, etc.) the different functionalities and features addressed and how they covered the specifications in the project proposal. The review discussions were documented for future analysis and also the reviewers sent an extensive report with their conclusions and concerns to improve in the next period.

This was a one-time method, which included objective and quantitative (the comparison of figures) feedback together with qualitative and subjective (the opinion and impressions) feedback. 


\section{G. Property checklists}

Property checklist [41] is a method where a usability expert goes through a checklist of design goals for different product properties (form, color, materials, graphics, sounds, functionality and interaction design).

This is a one-time method which was performed over the first main release. It is intended to be objective and qualitative but includes some subjectivity depending on the expert in charge. Again a report was generated with the properties that the platform does not fulfill.

\section{H. Interviews with potential users}

After the second ViSH release interviews with potential users were performed. These interviews were designed as a combination of other usability and UX methods. It was divided in two phases with several steps. After each step the users had to indicate their emotions with the use of expressive cartoon animations [42] and the intensity of these emotions on a scale from 0 to 10 .

In the first phase potential users saw the frontpage and a user homepage of $\mathrm{ViSH}$, and said what they thought these pages were for and what were the emotions that they had.

In the second phase the users were asked to do the five most important tasks in the ViSH platform using a thinking aloud technique [43]. Thereby they said aloud what they were thinking and feeling and what they were trying to do in every moment. After each task they had to indicate their emotions pointing one or more cartoons and the intensity for each one.

The interviewer did not help the users but saw their faces and where were they looking at to search for the proper functionalities. The screen and audio were recorded in every session so that they could be post processed to hear what was exactly said in every moment and to measure the task times and number of clicks. This method allowed obtaining quantitative data such as task success ratios, efficiency measures like task completion time or number of steps taken or user errors, and qualitative data like emotions and satisfaction expressed.

11 users were interviewed with a quite heterogeneous sample: 5 scientists and 6 teachers. None of them had previously accessed ViSH. The age range varies from 24 to 51. Some of them were used to learning platforms and some of them did not even know what e-Learning was.

This is a one-time method done after the second release. It combines quantitative and qualitative results and objective and subjective data.

\section{RESULTS}

This section presents the results of the survey conducted among all the development team members to discover the usefulness and effects of the usability and UX evaluation methods in their labors. The first five questions were intended to collect statistics and opinions: age, role, UX knowledge, what motivate them to learn about usability and UX and their opinion before the project started about the importance of usability and UX evaluation taking into account the software development stage.

The rest of the questions were to rate the usefulness of each evaluation method, see what do they considered the usability and UX evaluation useful for, and compare the overall usefulness of these methods with other factors that also influenced the software development like project meetings or documents.

The ViSH development team was composed by twelve members: one project manager, eight developers and three designers. These twelve subjects formed the sample of the presented study $(n=12)$. Ten of them were male and two were female. The average age was 31.7 years with a standard deviation (SD) of 9.36, and the average years of experience developing software was 9.2 years and 6.3 years developing websites.

Table 1 shows the usefulness of the different evaluation methods according to the development team ratings. The development team considers that the most useful methods were the "interviews with potential users" and "clickmaps and scrollmaps". The "project review", "sharing the designs in a blog" and "property checklists" were perceived as the least useful.

TABLE I. RAtings of the Evaluation Methods

\begin{tabular}{|l|c|c|}
\hline \multicolumn{1}{|c|}{ Evaluation method } & Usefulness 0-10 & SD \\
\hline \hline Participatory design & 7.0 & 1.81 \\
\hline $\begin{array}{l}\text { Share the designs in a blog and get } \\
\text { feedback through comments }\end{array}$ & 6.1 & 2.11 \\
\hline $\begin{array}{l}\text { Visitor analytics (server logs, Google } \\
\text { analytics) }\end{array}$ & 6.6 & 1.98 \\
\hline Clickmaps and scrollmaps (Crazyegg) & 8.3 & 1.66 \\
\hline $\begin{array}{l}\text { User feedback (email, Uservoice, } \\
\text { videoconference) }\end{array}$ & 7.4 & 2.02 \\
\hline $\begin{array}{l}\text { Project review by European Commission } \\
\text { reviewers }\end{array}$ & 6.1 & 1.68 \\
\hline Property checklists & 6.1 & 1.98 \\
\hline Interviews with potential users & 8.8 & 1.19 \\
\hline
\end{tabular}

When asked about what method they would remove ten members said that none of them and two agreed that they would remove the feedback about the designs in the blog. The question about adding additional methods was answered by three members with the request to hire a usability expert to conduct the same methods but in a more effective way. The tasks of the usability expert would be gathering the information, interpreting it and guiding the team to reach conclusions in an easier way. Other three members missed eye tracking and funneling, proposing tools like Mixpanel for this task.

Table 2 shows that the development team members considered that usability and UX evaluation allowed them mainly to "Improve the platform usability", "Identify design mistakes", "Understand the user and his/her needs in a better way" and "Improve the user satisfaction". On the other hand, "Reducing testing phase" and "Improving the platform aesthetics" was not considered very useful for them. 
TABLE II.

USEFULNESS OF USABILITY AND UX EVALUATION

\begin{tabular}{|l|c|c|}
\hline \hline UX and usability evaluation have allowed to & Rating 0-10 & SD \\
\hline \hline Improve the platform quality & 8.3 & 1.63 \\
\hline Improve the platform usability & 9.0 & 1.67 \\
\hline Improve the user satisfaction & 8.8 & 1.69 \\
\hline Improve the platform aesthetics & 4.8 & 1.98 \\
\hline Pick up new ideas & 7.5 & 1.51 \\
\hline $\begin{array}{l}\text { Understand the user and his/her needs in a } \\
\text { better way }\end{array}$ & 9.0 & 1.29 \\
\hline Be more efficient in ViSH development & 5.6 & 3.22 \\
\hline Prioritize tasks in a better way & 7.1 & 2.98 \\
\hline Identify design mistakes & 9.2 & 1.23 \\
\hline Identify bugs & 5.0 & 2.61 \\
\hline Reduce testing phase & 3.5 & 2.71 \\
\hline Be more satisfied with the result of my work & 7.5 & 2.82 \\
\hline Improve my professional skills & 8.5 & 1.98 \\
\hline
\end{tabular}

Table 3 shows the opinion of the members of the development team about the usefulness of several factors that likely influenced the software development. The factor perceived as most useful were "SCRUM meetings" followed by the "usability and UX evaluation methods". The worst rated factors were the "Description of Work" document and "meetings with the project manager". About other factors some members pointed out XP practices like pair programming as very useful. Other members highlighted the Workshop in Vienna (which is part of the participatory design) as a key milestone in the platform development.

TABLE III. USEFULNESS OF EACH FACTOR

\begin{tabular}{|l|c|c|}
\hline \hline \multicolumn{1}{|c|}{ Tool or factor } & $\begin{array}{c}\text { Usefulness } \\
\mathbf{0 - 1 0}\end{array}$ & SD \\
\hline \hline "Description of Work" document of the project & 4.3 & 2.35 \\
\hline In person and online meetings with the partners & 5.3 & 2.50 \\
\hline $\begin{array}{l}\text { Whole development group meetings (the 12 } \\
\text { together) }\end{array}$ & 5.8 & 2.52 \\
\hline SCRUM meetings & 8.6 & 1.00 \\
\hline $\begin{array}{l}\text { Small meetings with the project manager (2-3 } \\
\text { people with the project manager) }\end{array}$ & 5.0 & 2.56 \\
\hline Usability and UX evaluation methods & 8.5 & 1.57 \\
\hline
\end{tabular}

\section{DISCUSSION}

Several characteristics of this group may help understand the results of this study. In the first place the group members were quite young (31.7 years on average) and only the project manager was older than 36 years. This is especially important when referring to the designers, who were 26.6 years on average and were very inexperienced with 2.5 years on average developing and 1.5 years on average developing websites. They did not even know what UX was (or they had a fuzzy idea about what it meant) before this project started. The other nine members had more experience $(10.3$ years on average developing and 7.9 years on average developing websites) and all of them knew what UX was before starting the project.
Only three members of the team learnt about UX in their studies and all of them did it outside Spain, one in Illinois Institute of Technology in Chicago and two in Royal Institute of Technology in Sweden during scholarship periods. Finally to understand the results it is important to know that there was no usability or UX expert in this group, so the data gathered with the different evaluation methods was processed by the development team members and presented in meetings where decisions were made by group agreement.

About the usefulness of the usability and UX evaluation methods on their labor, when we asked to the development team members about the results they answered that "interviews with potential users" were the most powerful method as it combined several approaches and was very complete, and "clickmaps and scrollmaps" were easy to understand, easy to work with them, very visual and aggregate the data of all the users visiting the platform not only the ones that report a problem. This result fits in with the conclusion reached by [44], where the authors state that "as usability professionals with the goal of being more effective in our work, we need to be more positive, clear, precise, and respectful in our communications about problems and solutions".

According to the study done by [45] regarding feedback formats, "developers rated the multimedia presentation, redesign proposals and the screen dump format highest". In our case the recordings of the interviews with potential users were in multimedia format and the "clickmaps and scrollmaps" were screenshots with extra added information.

Special mention here to "User feedback" method, that although had a good rating it was the target of several comments like "this feedback has to be treated with care", "we can't pay attention or design for one or few users" or "I prefer to take into account what the user does instead of what the user says".

Finally the "participatory design" methods had a relatively high perceived usefulness, but it is worth pointing out the difference between the ratings of the people who assisted to the workshop (project manager and two developers, that rated it with an average of 9.3) and the ratings of the members who did not assist that workshop (the rest of the team, that rated it with an average of 6.2). We can observe here that the perceived usefulness is much bigger for people who participated in the process as they were able to interact in person with the target users, talk to them and design the scenarios together.

The assisting developers stood that "this was a very grateful experience" and that "they liked to participate in the design process", finally "it made them feel appreciated". On the other hand non-assisting members saw the participatory design as "the place where their ideas were discarded" and made them "feel unappreciated". Also, this fact exposes a possible lack of communication among development team members inside the organization, since the usefulness perceived by the workshop assistants was not transferred to the rest of the team. 
The development team found UX and usability methods useful for identifying design mistakes but not for improving platform aesthetics. Designers confirmed that the ViSH look and feel had been kept from the first alpha release (with only slight changes), that they "cannot obey all opinions and feedback about look and feel, because in that case everything would be a mess and nothing would match a proper design line". On the contrary, several design mistakes were identified by these methods and so the team recognized that they were very useful for that task.

Finally, it is worth mentioning the importance of educating all people involved in the software development process about usability and UX. In our case before the project starts, designers believed, due to their lack of experience, that these methods were only really useful before starting the development (about ideas, concepts or prototypes) while developers considered them useful in all stages.

At this time and based on the results of the survey, we can state that the whole team considered usability and UX evaluation very useful in all development stages. Also, all development team members unanimously considered that this experience of introducing these methods into the software development process allowed them to improve their professional skills.

\section{CONCLUSIONS}

This study investigated how several UX and usability evaluation methods influenced the software development of an e-Learning platform. What was the most useful method from the ones used, in what way these methods influenced different issues in the development and how was their perceived usefulness in comparison with other factors.

During the development of ViSH, eight UX and usability evaluation methods were employed. Interviews with potential users, clickmaps and scrollmaps were rated as the most useful methods by the development team members. The impact of this evaluation on the ViSH platform was strong from a developer's perspective. Developer team members considered that UX and usability evaluation allowed them mainly to improve the platform usability, identify design mistakes and understand the end users and their needs in a better way. Finally these methods were considered unanimously very useful in the context of the entire software development, only comparable to SCRUM meetings overcoming the rest of involved factors.

On the other hand, ViSH developers did not consider useful the UX evaluation methods neither for reducing testing phase nor improving the platform aesthetics. Furthermore, non-SCRUM meetings and initial project documents were not considered very useful.

Another question to be asked is how much influence the used tool in the usefulness of an evaluation method. To answer this question, we would like to replace some of the current tools for others more powerful (with more investment) in order to compare the considered usefulness of the evaluation method in the two cases (with the new and the old tool).
Considering that ViSH can be accessed from mobile phones, tablets and desktop computers, we plan to evaluate the influence and usefulness of the UX and usability evaluation methods when handheld devices come into play.

\section{TIPS FOR USABILITY PRACTITIONERS}

Finally, although these research conclusions are very dependent on the development group characteristics we would like to conclude this paper with some lessons learnt, recommendations and possibilities of improvement.

- Count on a usability and UX expert. A medium or large development group should count on an expert or at least delegate this task to one of the senior members of the team. This would allow to properly select the usability and UX methods to apply, to gather the information collected with the different methods, to process it with a unified criterion and finally to generate a report and explain it to the rest of the team. We think this way the collected feedback would be more persuasive to the development team.

- Corroborate feedback. Direct feedback from users about usability and UX issues have to be corroborated with feedback from other methods. The development team cannot be paying attention to individual opinions except they are supported by data.

- Involve the participation of the whole development team. If any method involves development team members, the whole group should assist if possible. If this is not a possibility the assisting members should prepare a report with detailed explanations of the decisions taken. This fact would make this method more useful and persuasive for the whole development team and not only to the participating members.

- Introduce UX in the curriculum. Although UX is a quite modern field all developers and designers should at least know what it is and have some basic notions. We strongly recommend introducing this discipline in the curriculum.

\section{ACKNOWLEDGEMENTS}

We wish to acknowledge our gratitude and appreciation to all the GLOBAL excursion project partners, and each one of the project team members, for their contribution to this paper.

\section{REFERENCES}

[1] C. Ardito, P. Buono, D. Caivano, M. F. Costabile, R. Lanzilotti, A. Bruun, and J. Stage, "Usability evaluation: a survey of software development organizations.," 2011, pp. 282 - 287.

[2] C. Ardito, P. Buono, M. F. Costabile, and R. Lanzilotti, "Are software companies aware of UX?," in I-UxSED'12, 2012, pp. 10-13.

[3] M. Kuniavsky, Observing the User Experience: A Practitioner's Guide to User Research. Morgan Kaufmann, 2003, p. 576. 
[4] T. Holocher-ertl, B. Kieslinger, and C. M. Fabian, "Linking schools with science: How innovative tools can increase the effectiveness of science teaching in the classroom," in Proceedings of the 2012 EDEN Annual Conference: Open Learning Generations - Closing the Gap from «Generation Y» to the Mature Lifelong Learners, 2012.

[5] E. Barra, A. Gordillo, and J. Quemada, "Virtual Science Hub: An Open Source Platform To Enrich Science Teaching," in Proceedings of the International Conference on Educational Sciences and Technology (ICEST 2014), 2014.

[6] A. Gordillo, E. Barra, and J. Quemada, "Enhancing K-12 science education through a multi-device web tool to facilitate content integration and e-Infrastructure access," in Proceedings of the 7th International Technology, Education and Development Conference (INTED 2013), 2013.

[7] E. Barra, D. Gallego, S. Aguirre, and J. Quemada, "Facilitating the creation of K-12 interactive learning objects using a multi device web tool," in Proceedings of the 2012 Frontiers in Education Conference (FIE 2012), 2012.

[8] E. Barra, D. Gallego, S. Aguirre, and J. Quemada, "A web tool to create educational content with gaming visualization," in Proceedings of the 2012 Frontiers in Education Conference (FIE 2012), 2012.

[9] ISO, "ISO 9241-11: Ergonomic requirements for office work with visual display terminals (VDTs) -- Part 11: Guidance on usability," 1998.

[10] H. R. Hartson, T. S. Andre, R. C. Williges, and V. Tech, "Criteria for evaluating usability evaluation methods," International journal of human-computer interaction, vol. 13, no. 4, pp. 373-410, 2001.

[11] C. Quintana, A. Carra, J. Krajcik, and E. Soloway, "Learner-Centered Design: Reflections and New Directions," in Human-Computer Interaction in the New Millennium, Addison Wesley, 2001, pp. 605-626.

[12] C. Ardito, M. F. Costabile, M. De Marsico, R. Lanzilotti, S. Levialdi, T. Roselli, and V. Rossano, "An approach to usability evaluation of e-learning applications," Universal Access in the Information Society, vol. 4, no. 3, pp. 270-283, 2006

[13] M. N. Giannakos, "The evaluation of an e-Learning web-based platform," in Proceedings of the 2nd International Conference on Computer Supported Education, 2010, pp. 433-438.

[14] D. Norman, J. Miller, and A. Henderson, "What you see, some of what's in the future, and how we go about doing it," in Conference companion on Human factors in computing systems - CHI '95, 1995.

[15] ISO, "ISO 9241-210: Ergonomics of human system interaction Part 210: Human-centred design for interactive systems.," 2010.

[16] "UX Definitions." [Online]. Available: http://www.allaboutux.org/ux-definitions.

[17] E. Law, V. Roto, M. Hassenzahl, A. Vermeeren, and J. Kort, "Understanding, scoping and defining user experience," in Proceedings of the 27th international conference on Human factors in computing systems - CHI 09, 2009, p. 719.

[18] M. Hassenzahl, M. Burmester, and F. Koller, "AttrakDiff: A Questionnaire for Measuring the Perceived Hedonic and Pragmatic Quality," Human \& Computer, pp. 187-196, 2003.

[19] E. Karapanos, J.-B. Martens, and M. Hassenzahl, "Reconstructing Experiences through Sketching. rxiv preprint arXiv:0912.5343," 2009.

[20] K. Isbister, K. Höök, M. Sharp, and J. Laaksolahti, “The sensual evaluation instrument," in Proceedings of the SIGCHI conference on Human Factors in computing systems - CHI '06, 2006, p. 1163

[21] E. Karapanos, J. Zimmerman, J. Forlizzi, and J.-B. Martens, "User experience over time," in Proceedings of the 27th international conference on Human factors in computing systems - CHI 09, 2009.

[22] V. Roto, E. Law, A. Vermeeren, and J. Hoonholt, "User experience white paper," in Results from Dagstuhl Seminar on Demarcating User Experience, 2011.

[23] A. Vermeeren, E. Law, V. Roto, M. Obrist, J. Hoonhout, and K. Väänänen-Vainio-Mattila, "User experience evaluation methods," in Proceedings of the 6th Nordic Conference on Human-Computer Interaction Extending Boundaries - NordiCHI '10, 2010, p. 521.
[24] E. Law, S. Abrahão, A. Vermeeren, and E. Hvannberg, "Interplay between User Experience Evaluation and System Development: State of the Art," in International Workshop on the Interplay between User Experience (UX) Evaluation and System Development, 2012, p. 1.

[25] M. Budwig, S. Jeong, and K. Kelkar, "When user experience met agile," in Proceedings of the 27th international conference extended abstracts on Human factors in computing systems - CHI EA '09, 2009, p. 3075.

[26] T. Jokela, "The early phases of UX: Why they are important (more than evaluation), and what they are?," in International Workshop on the Interplay between User Experience (UX) Evaluation and System Development, 2012, p. 49.

[27] C. Larman, Agile and Iterative Development: A Manager's Guide. Addison-Wesley Professional, 2003.

[28] L. Rising and N. S. Janoff, "The Scrum software development process for small teams," IEEE Software, vol. 17, no. 4, pp. 26-32, 2000.

[29] D. Thomas, D. H. Hansson, L. Breedt, M. Clark, T. Fuchs, and A. Schwarz, Agile Web Development with Rails: A Pragmatic Guide (Pragmatic Programmers). Pragmatic Bookshelf, 2005, p. 450.

[30] A. Dix, J. E. Finlay, G. D. Abowd, and R. Beale, Human-Computer Interaction (3rd Edition). Prentice Hall, 2003, p. 834.

[31] T. Tullis and W. Albert, Measuring the User Experience: Collecting, Analyzing, and Presenting Usability Metrics. Morgan Kaufmann, 2008

[32] M. J. Muller and S. Kuhn, "Participatory design," Communications of the ACM, vol. 36, no. 6, pp. 24-28, Jun. 1993.

[33] J. M. Carroll, "Five reasons for scenario-based design," Interacting with Computers, vol. 13, no. 1, pp. 43-60, Sep. 2000.

[34] K. Isacker, K. Slegers, M. Gemou, and E. Bekiaris, Universal Access in Human-Computer Interaction. Addressing Diversity, vol. 5614. Berlin, Heidelberg: Springer Berlin Heidelberg, 2009, pp. 184-192.

[35] P. K. Huntwork, D. W. Muzzey, C. M. Pietras, and D. R. Wixon, "Changing the rules: a pragmatic approach to product development," Digital Technical Journal, vol. 5, no. 4, pp. 18-35, 1993.

[36] T. Holocher-Ertl, B. Kieslinger, and C. . Fabian, "Designing for the Users or with the Users? A Participatory Design Approach for Science Teaching in Schools," in Proceedings of the 22nd annual eChallenges e-2012 Conference, 2012.

[37] "GLOBAL excursion teachers blog." [Online]. Available: http://teacher.globalexcursion-project.eu.

[38] “CrazyEgg tool.” [Online]. Available: http://www.crazyegg.com.

[39] “MashMeTV.” [Online]. Available: http://www.mashme.tv.

[40] “UserVoice tool." [Online]. Available: http://www.uservoice.com.

[41] P. W. Jordan, Designing Pleasurable Products: An Introduction to the New Human Factors. CRC Press, 2000.

[42] P. Desmet, Measuring emotion: development and application of an instrument to measure emotional responses to products. 2005.

[43] M. W. van Someren, Y. F. Barnard, and J. A. C. Sandberg, The Think Aloud Method: A Practical Guide to Modelling Cognitive Processes (Knowledge-Based Systems). Academic Press, 1994, p. 208.

[44] J. S. Dumas, R. Molich, and R. Jeffries, "Describing Usability Problems: Are we sending the right message?," interactions, vol. 11, no. 4, p. 24, 2004.

[45] M. NØrgaard and K. Hornbæk, "Exploring the Value of Usability Feedback Formats," International Journal of Human-Computer Interaction, vol. 25, no. 1, pp. 49-74, 2009. 